Retrospective Study

\title{
Full-Endoscopic Technique Discectomy Versus Microendoscopic Discectomy for the Surgical Treatment of Lumbar Disc Herniation
}

Mao Li, MD¹, Huilin Yang, MD¹, and Qun Yang, MD²

From: ${ }^{1}$ The First Affiliated Hospital of Soochow University Suzhou, Jiangsu Province China; ${ }^{2}$ The First Affiliated Hospital of Dalian medical University, Dalian, Liaoning Province, China

Address Correspondence: Huilin Yang, MD The First Affiliated Hospital of Soochow University Department of Orthopaedics 188 Shizi Street

Suzhou, Jiangsu Province China E-mail:

yhlpaper@163.com

Disclaimer: There was no external funding in the preparation of this manuscript. Conflict of interest: Each author certifies that he or she, or a member of his or her immediate

family, has no commercial association (i.e., consultancies, stock ownership, equity interest, patent/licensing arrangements, etc.) that might pose a conflict of interest in connection with the submitted manuscript.

Manuscript received: 11-10-2014 Revised manuscript received: 02-05-2015 Accepted for publication: 03-02-2015

Free full manuscript: www.painphysicianjournal.com
Background: Full-endoscopic technique discectomy (FED) or microendoscopic discectomy (MED) are 2 widely used minimally invasive procedures for the treatment of lumbar disc herniation. However, there is insufficient literature regarding the differences between these 2 surgical procedures.

Objective: To compare the clinical outcomes of 2 different minimally invasive methods-fullendoscopic technique discectomy and microendoscopic discectomy-in the surgical treatment of lumbar disc herniation.

Study Design: Retrospective study.

Setting: Inpatient surgery center.

Methods: Data form 65 patients with lumbar disc herniation treated with one of 2 minimally invasive procedures were retrospectively analyzed. Patients were divided into 2 groups according to surgical method: the FED group $(n=35)$ and the MED group $(n=30)$. Surgery time, time kept in bed after surgery, duration of postoperative hospital stay, visual analog scale (VAS; $0-10$ ), and Oswestry Disability index (ODI; 0 - 100\%) were assessed and compared between the 2 groups.

Results: There were no significant differences in the preoperative data between the 2 groups $(P>$ 0.05). VAS and ODI scores improved significantly postoperatively in both groups $(P<0.05)$. Surgery time was longer in the FED group than in the MED group $(P<0.05)$. However, the FED group was superior to the MED group, with less time in bed, shorter hospital stay, and lower VAS scores one day postoperatively $(P<0.05)$. There were no significant differences in VAS or ODI scores at one, 3 , and 12 months after surgery between the 2 groups $(P>0.05)$.

Limitations: This is a retrospective study with a relatively short follow-up period.

Conclusions: Although the clinical outcomes of the 2 surgical techniques were similar, the FED had the advantages of quicker postoperative recovery and more immediate effect.

Key words: Full-endoscopic, microendoscopic, discectomy, lumbar disc herniation, minimally invasive, surgical treatment

Pain Physician 2015; 18:359-363 umbar disc herniation is one of the most common pathologic processes for which patients seek surgical spinal treatment. Even though laminotomy and discectomy can achieve satisfactory results (1), spine surgeons prefer minimally invasive procedures with less trauma and quicker recovery, such as full-endoscopic technique discectomy (FED) or microendoscopic discectomy (MED), which are widely used for the treatment of lumbar disc herniation and also achieve satisfactory clinical outcomes (2-7). The 
FED interlaminar approach and MED are similar, making it sometimes difficult for surgeons to choose between the procedures.

There is insufficient literature regarding the differences between these 2 surgical procedures. Therefore, we analyzed the data on 65 patients with lumbar disc herniation treated with either the FED or MED between December 2010 and May 2012.

\section{Methods}

\section{General Materials}

We used the following inclusion criteria: (1) singlelevel, soft herniated disc at the L4/L5 or L5/S1 level, (2) positive Lasegue's sign with unilateral radicular pain, (3) standard conservative treatment for at least 2 months prior to surgical treatment, (4) follow-up over one year, (5) treated between December 2010 and May 2012. Exclusion criteria included the following: (1) underlying disease, such as uncontrolled myocardial ischemia, diabetes; (2) surgical history involving the lumbar spine; (3) cauda equina syndrome or spinal instability; (4) radiographic data not in accordance with his/her clinical symptoms and signs.

Every patient should meet all the inclusion criteria and mustn't meet any of the exclusion criteria. There were 65 patients complying with all conditions.

Patients were divided into 2 groups according to surgical procedure: the FED group or the MED group. There were 20 men and 15 women in the FED group, with an average age of 37.5 years (range, $26-50$ years). Meanwhile, there were 17 men and 13 women in the MED group, with an average age of 37.8 years (range, $24-51$ years). There were no significant differences in the preoperative data between the 2 groups $(P>0.05)$ (Table 1).
In this study, both FED and MED were inpatient procedures. All operations were performed by 2 experienced spine surgeons, one performed only FED, and another performed only MED. Patients decided which surgeon would be in charge of their treatment all by themselves.

\section{Surgical Technique}

In the FED group, there were 14 patients with a herniated disc at the L4/L5 level who underwent a FED transforaminal approach, and 21 patients with a herniated disc at the L5/S1 level who underwent a FED interlaminar approach. The FED transforaminal procedure was performed under sedation and local anesthesia, with the patient positioned prone. With $\mathrm{x}$ ray guidance, a needle was introduced between 10 and $15 \mathrm{~cm}$ from the midline of the spine to the herniated disc. The needle should go through the caudal part of the transforamen. The needle then was removed, leaving the guidewire in situ. Then, an 8-mm skin incision was made, and a cannulated dilator and surgical sheath with beveled opening were inserted. Decompression was performed under constant irrigation. The patient was told to alert the surgeon if he/she experienced any pain. The surgical sheath was removed and the wound was intradermically sutured. The FED interlaminar procedure was performed under general anesthesia and endotracheal intubation, with the patient positioned kneeling prone to achieve a wider interlaminar window space. After confirming the surgical segment with x-ray fluoroscopy, an 8-mm incision was made. Then, a dilator was inserted through the incision. Afterward, an operating sheath was inserted through the dilator, with its beveled opening toward the spinous processes. After removing the dilator and inserting the endoscope, the procedure was performed under constant irrigation.

Table 1. The general data of the patients in both groups (mean $\pm S D$ ).

\begin{tabular}{|c|c|c|c|c|c|}
\hline \multirow{2}{*}{ Group } & \multirow{2}{*}{ Case } & \multirow{2}{*}{$\begin{array}{c}\text { Age } \\
\text { (year) }\end{array}$} & \multicolumn{2}{|c|}{ Gender } & \multirow{2}{*}{$\begin{array}{c}\text { Duration } \\
\text { (month) }\end{array}$} \\
\hline & & & male & female & \\
\hline FED group & 35 & $37.5 \pm 5.5$ & 20 & 15 & $16.2 \pm 4.2$ \\
\hline MED group & 30 & $37.8 \pm 6.6$ & 17 & 13 & $15.4 \pm 4.8$ \\
\hline
\end{tabular}

\begin{tabular}{|c|c|c|c|}
\hline \multirow{2}{*}{ Preoperative VAS } & \multirow{2}{*}{ Preoperative ODI } & \multicolumn{2}{|c|}{ Lesion Segment } \\
\cline { 3 - 4 } & & L4/L5 & L5/S1 \\
\hline $8.1 \pm 1.1$ & $56.1 \pm 14.0$ & 14 & 21 \\
\hline $7.9 \pm 1.2$ & $54.1 \pm 12.7$ & 11 & 19 \\
\hline
\end{tabular}

Notice: The comparison of the 2 groups, $P>0.05$. 
After removing the hernia and surgical sheath, intradermic suturing was performed.

In the MED group, the procedure was performed under general anesthesia and endotracheal intubation, with the patient positioned kneeling prone. After confirming the surgical segment with x-ray fluoroscopy, a $1.8-\mathrm{cm}$ incision was made. Then, multiple-level dilators were inserted and the operating sheath was fixed. Subsequently, an endoscope was inserted and the procedure was performed under visual control. Finally, drainage tubes were inserted and intradermic suturing was performed.

Surgery time, time kept in bed after surgery, duration of postoperative hospital stay, visual analog scale (VAS) score at one day, and one, 3, and 12 months after surgery, and Oswestry Disability Index (ODI) score at one, 3, and 12 months after surgery were recorded. All data were analyzed using the program package SPSS 17.0 (SPSS, US). Measurement data were compared using $t$ test analysis or analysis of variance, while count data were compared using the chi-square test. A positive significance level was assumed at a probability of less than 0.05 .

\section{Results}

One patient in the FED group experienced a dural tear. Since the tear was minor, we did not treat it, and the patient was asymptomatic postoperatively. There were no intraoperative or postoperative complications in the MED group. VAS and ODI scores improved signifi- cantly postoperatively in each group $(P<0.05)$. Thirtytwo patients reported subjective satisfaction in the FED group (91\%) and 28 patients did in the MED group $(93 \%)$. There were no significant differences $(P>0.05)$. Surgery time was longer in the FED group than in the MED group $(P<0.05)$. The FED group was superior to the MED group, however, with less time in bed, shorter hospital stay $(P<0.05)$ (Table 2$)$, and lower VAS scores one day postoperatively $(P<0.05)$ (Table 3$)$. There were no significant differences in VAS or ODI scores at one, 3 , and 12 months after surgery between the 2 groups $(P>0.05)$ (Table 3). Overall, recurrence was observed in 5 patients, 3 times in the FED group (8.6\%) (one with the transforaminal approach, $7.1 \% ; 2$ with the interlaminar approach, 9.5\%) and 2 times in the MED group (6.7\%). There were no significant differences $(P>0.05)$.

\section{Discussion}

Compared with conventional surgery, MED magnifies the operative field with an advanced camera system so that the surgeon can identify and protect nerve tissue more easily, with good or excellent results reported in $92.1-97 \%$ of cases (3). Although MED has the advantages of less paraspinal muscle dissection, less bone and joint destruction, less spinal stability breach, less blood loss, and quicker postoperative recovery (4), it is essentially the minimally invasive endoscopic form of conventional surgery. It is inevitable in MED to touch and drag the nerve root and dura mater and resect part of the ligamentum flavum and lamina; this

Table 2. The comparison of the postoperative related date of the patients in each group (mean $\pm S D$ ).

\begin{tabular}{|c|c|c|c|}
\hline Group & Operation time (min) & Time in bed (hours) & Hospital stay (days) \\
\hline FED group & $102.9 \pm 12.3$ & $3.7 \pm 1.6$ & $1.5 \pm 0.6$ \\
\hline MED group & $58.5 \pm 9.0$ & $13.6 \pm 5.3$ & $2.3 \pm 0.7$ \\
\hline
\end{tabular}

Notice: The comparison of the 2 groups, $P<0.05$.

Table 3. VAS and ODI scores for the patients in each group (mean $\pm S D$ ).

\begin{tabular}{|l|c|c|c|c|c||}
\hline Group & Preoperative & $\begin{array}{c}\text { 1 day } \\
\text { Postoperative }\end{array}$ & $\begin{array}{c}\text { 1 month } \\
\text { Postoperative }\end{array}$ & $\begin{array}{c}\text { 3 months } \\
\text { Postoperative }\end{array}$ & $\begin{array}{c}\text { 12 months } \\
\text { Postoperative }\end{array}$ \\
\hline VAS scores & \multicolumn{5}{|l||}{} \\
\hline FED group & $8.1 \pm 1.1$ & $2.7 \pm 0.8$ & $2.2 \pm 0.6$ & $2.0 \pm 0.7$ & $1.8 \pm 0.8$ \\
\hline MED group & $7.9 \pm 1.2$ & $3.8 \pm 0.7$ & $2.5 \pm 0.6$ & $2.2 \pm 0.6$ & $1.8 \pm 0.8$ \\
\hline \multirow{2}{*}{ ODI scores } & $56.1 \pm 14.0$ & - & $19.1 \pm 5.5$ & $13.7 \pm 5.1$ & $9.7 \pm 6.8$ \\
\cline { 2 - 7 } & $54.1 \pm 12.7$ & - & $20.9 \pm 6.1$ & $15.2 \pm 5.4$ & $9.1 \pm 6.1$ \\
\hline
\end{tabular}

Notice: VAS and ODI scores improved significantly postoperatively in each group $(P<0.05)$; There is significant differences between the VAS scores of the 2 groups 1 day postoperatively $(P<0.05)$; Comparing the condition $1,3,12$ months postoperatively, the result was not statistically significant $(P>0.05)$. 
can lead to intraspinal adhesions. Consequently, some surgeons prefer FED, the transforaminal approach in particular, to avoid the problems associated with MED. FED has similar clinical outcomes and rates of recurrence and complications compared with conventional spinal surgery (7-12). Ruetten et al (7) and Birkenmaier et al (9) showed that FED has the advantages of not cutting the lamina and very little damage to the paravertebral muscles, ligaments, and intraspinal tissues, which conforms more to the concept of minimally invasive surgery. In our study, we also demonstrated that FED was superior to MED with better immediate clinical outcomes and quicker recovery.

In the FED group, there was one occurrence of dural tear $(2.9 \%)$. There was no occurrence of dural tear or nerve root injury in the MED group. It has been reported that the risks of dural tear and nerve root injury with FED are only $1.1 \%$ and $2 \%$, respectively, which are similar to those with $\operatorname{MED}(13,14)$. Thus, we believe that both FED and MED are safe procedures. The reported recurrence rate of FED is approximately $8 \%$, which is comparable with the $5 \%$ recurrence rate of MED (15). Both recurrence rates are also comparable with that of conventional fenestration surgery (16).

In our study, compared with MED, FED had the advantages of better immediate clinical outcomes and quicker recovery. It also had some disadvantages, however. Operating time was longer than that with MED. In addition, for surgeons, it takes a long time to master FED (17). The exploration scope with FED is less than that with MED, which may lead to disc residue. Furthermore, indications for FED are fewer than those for MED. The FED technique is more adapted to simple lumbar disc herniation. For patients with huge lumbar disc herniation or obvious disc shift, the failure rate of FED is high (18). It is difficult with FED to achieve sufficient decompression in patients with ossification of posterior longitudinal ligament (OPLL), vertebrae posterior marginal osteoproliferation, or lumbar stenosis. With MED, however, it may not be so difficult $(2,4)$.

Because of blocking of the crista iliaca, we chose a FED approach or MED to treat patients with a herniated disc at the L5/S1 level. Although a FED interlaminar approach is more minimally invasive, MED involves full exposure, a simple operation, and is easier to master for a beginner. We advise that beginning surgeons should start with a FED interlaminar approach after mastering MED.

Because the starting point of the $\mathrm{S} 1$ nerve root is at a more cephalad level, the angle between the S1 nerve root (19) and dura mater is so large (20) that when performing a FED interlaminar procedure, it is better to decompress the "axillary" of the $S 1$ nerve root initially, and then the "shoulder" of the $\mathrm{S1}$ nerve root. This method not only provides more operating space but also prevents injury of the S1 nerve root, because when the operating sheath is shifted from "shoulder" to "axillary," the sheath may extrude the nerve root with a huge herniated disc "axillary."

\section{Conclusions}

Both FED and MED are safe and effective for the treatment of lumbar disc herniation. However, the FED technique is more minimally invasive in our opinion.

\section{References}

1. Hoffman RM, Wheeler KJ, Deyo RA. Surgery for herniated lumbar discs: A literature synthesis. J Gen Intern Med 1993; 8:487-496.

2. Smith N, Masters J, Jensen C, Khan A, Sprowson A. Systematic review of microendoscopic discectomy for lumbar disc herniation. Eur Spine J 2013; 22:2458-2465.

3. Brayda-Bruno M, Cinnella P. Posterior endoscopic discectomy (and other procedure). Eur Spine J 2000; 9:S24-S29.

4. Wang M, Zhou Y, Wang J, Zhang Z, Li C. A 10-year follow-up study on long-term clinical outcomes of lumbar microendoscopic discectomy. J Neurol Surg A Cent
Eur Neurosurg 2012; 73:195-198.

5. Ruetten S, Komp M, Godolias G. A New full-endoscopic technique for the interlaminar operation of lumbar disc herniations using 6-mm endoscopes: Prospective 2-year results of 331 patients. Minim Invasive Neurosurg 2006; 49:80-87.

6. Jasper GP, Francisco GM, Telfeian AE. Endoscopic transforaminal discectomy for an extruded lumbar disc herniation. Pain Physician 2013; 16:E31-E35.

7. Ruetten S, Komp M, Merk H, Godolias G. Use of newly developed instruments and endoscopes: Full-endoscopic resection of lumbar disc herniations via the interlaminar and lateral transforami- nal approach. J Neurosurg Spine 2007; 6:521-530.

8. Kim MJ, Lee SH, Jung ES, Son BG, Choi ES, Shin JH, Sung JK, Chi YC. Targeted percutaneous transforaminal endoscopic discectomy in 295 patients: Comparison with results of microscopic discectomy. Surg Neurol 2007; 68:623-631.

9. Birkenmaier C, Komp M, Leu HF, Wegener $\mathrm{B}$, Ruetten $\mathrm{S}$. The current state of endoscopic discsurgery: Review of controlled studies comparing full-endoscopic procedures for disc herniations to standard procedures. Pain Physician 2013; 16:335-344.

10. Lee SH, Chung SE, Ahn Y, Kim TH, Park 
JY, Shin SW. Comparative radiologic evaluation of percutaneous endoscopic lumbar discectomy and open microdiscectomy: A matched cohort analysis. $\mathrm{Mt}$ Sinai ] Med 2006; 73:795-801.

11. Tsou PM, Yeung AT. Transforaminal endoscopic decompression for radiculopathy secondary to intracanal noncontained lumbar disc herniations: Outcome and technique. Spine J 2002; 2:41-48.

12. Rasouli MR, Rahimi-Movaghar V, Shokraneh F, Moradi-Lakeh M, Chou R. Minimally invasive discetomy versus microdiscetomy/open discectomy for symptomatic lumbardisc herniation. Cochrane Database Syst Rev 2014; 9:CDolo328.

13. Gotfryd A, Avanzi O. A systematic review of randomized clinical trials using pos- terior discectomy to treat lumbar disc herniations. Int Orthop 2009; 33:11-17.

14. Ahn Y, Lee HY, Lee SH, Lee JH. Dural tears in percutaneous endoscopic lumbar discectomy. Eur Spine J 2011; 20:58-64.

15. Ng CY, Gibson JN. An aid to the explanation of surgical risks and complications: The International Spinal Surgery Information Sheet. Spine (Phila Pa 1976) 2011; 36:2333-2345.

16. Kim CH, Chung CK, Park CS, Choi B, Kim MJ, Park BJ. Reoperation rate after surgery for lumbar herniated intervertebral disc disease: Nationwide cohort study. Spine (Phila Pa 1976) 2013; 38:581-590.

17. Hsu HT, Chang SJ, Yang SS, Chai CL. Learning curve of full-endoscopic lumbar discectomy. Eur Spine J 2013; 22:727-733.

18. Lee SH, Kang BU, Ahn Y, Choi G, Choi YG, Ahn KU, Shin SW, Kang HY. Operative failure of percutaneous endoscopic lumbar discectomy: A radiologic analysis of 55 cases. Spine (Phila Pa 1976) 2006; 31:E285-E290.

19. Suh SW, Shingade VU, Lee SH, Bae JH, Park CE, Song JY. Origin of lunbar spinal roots and their relationship to intervertebral discs: A cadaver and radiological study. J Bone Joint Surg Br 2005; 87:518-522.

20. Hasegawa T, Mikawa Y, Watanabe R, An HS. Morphometric analysis of the lumbosacral nerve roots and dorsal root ganglia by magnetic resonance imaging. Spine (Phila Pa 1976) 1996; 21:1005-1009. 
